\title{
PENGARUH VARIASI KECEPATAN MOTOR PADA MESIN PENGHALUS PERMUKAAN TIPE DISC DAN BELT TERHADAP TINGKAT KEKASARAN PERMUKAAN BENDA KERJA
}

\section{EFFECT OF VARIATION TO MOTORCYCLE ON ENTERPRISE SURFACE TYPES OF DISC AND BELT ON SURFACE BOTTLESENCE OF WORKING OBJECTS}

\author{
Moh. Hasan Noval ${ }^{1 *}$, Nely Ana Mufarida, S.T., M.T. $^{2}$ Asmar Finali, S.T., M.T. ${ }^{3}$ \\ ${ }^{1}$ Mahasiswa, ${ }^{2}$ Dosen Pembimbing $1,{ }^{3}$ Dosen Pembimbing 2, Program Studi Teknik Mesin, Fakultas \\ Teknik, Universitas Muhammadiyah Jember \\ "Email : noval.maulana19@yahoo.com
}

\begin{abstract}
ABSTRAK
Amplas atau disebut kertas pasir yaitu sejenis kertas yang digunakan untuk membuat permukaan benda-benda menjadi lebih halus. Mesin penghalus otomatis dibuat untuk mengedepankan keunggulan tingkat akurasi dan presisi yang lebih tinggi sehingga mempermudah hasil yang diperoleh. Spesifikasi dari alat tersebut adalah dengan menggunakan driver motor $\mathrm{AC}$ untuk mengatur kecepatan putaran motor AC (dynamo). Untuk bahan pengujian menggunakan 9 kubus kayu berukuran sisi $30 \mathrm{~mm}$. Pengujian dilakukan untuk mengetahui tingkat kekasaran permukaan benda kerja pada masing-masing kecepatan 1100 RPM, 1300 RPM dan 1500 RPM. Selanjutnya akan dicari nilai rata-rata dari setiap kecepatan putaran motor yang berbeda-beda untuk mengetahui besar dari nilai kekasaran dan keausan pada benda kerja. Nilai kecepatan putaran diukur menggunakan Tachometer sedangkan output tegangan listrik diukur menggunakan AVO meter digital. Setelah diukur data akan ditulis untuk mengetahui variasi kecepatan putaran motor yang diatur menggunakan driver motor.

Kata kunci : driver motor AC, motor AC, kekasaran permukaan benda kerja.
\end{abstract}

ABSTRACT

Sandpaper or called sand paper is a kind of paper that is used to make the surface of objects become more subtle. Automatic smoothing machines are designed to promote the superiority of accuracy and higher precision to facilitate the results obtained. The specification of the tool is to use AC motor driver to adjust the speed of rotation of AC motor (dynamo). For material testing using 9 wooden cubits sized $30 \mathrm{~mm}$. The test was conducted to determine the level of surface roughness of the workpiece at 1100 RPM, 1300 RPM and 1500 RPM respectively. Furthermore, we will look for the average value of each motor rotation speed is different to know the magnitude of the roughness and wear and tear on the workpiece. The rotation speed value is measured using a Tachometer while the output voltage is measured using a digital AVO meter. After the measured data will be written to know the motor rotation speed variation that is set using motor driver.

Keywords: AC motor driver, AC motor, surface roughness of workpiece

\section{PENDAHULUAN}

Di Indonesia kebutuhan akan kerajinan atau alatalat pertukangan semakin meningkat pesat. Seiring dengan perkembangan jumlah penduduk Indonesia yang semakin besar serta semakin banyak industri kerajinan terutama industri rumahan yang berbahan baku kayu dan besi. Salah satu contoh industri kerajinan kayu dan tulang hewan yang terdapat di desa Balung Jember Jawa Timur, memproduksi bahan hasil pengolahan kayu dan tulang yang dihaluskan dengan amplas. Amplas atau biasa disebut kertas pasir yaitu sejenis kertas yang digunakan untuk membuat permukaan benda-benda menjadi lebih halus dengan cara menggosokan salah satu permukaan amplas yang telah ditambahkan bahan yang kasar kepada permukaan benda tersebut. Pada penelitian sebelumnya milik Agung Kristanto dan Tri Sugiantoro [1] yang berjudul "Perencangan Ulang Mesin Amplas Kayu Profil Lengkung Untuk Perbaikan Posisi Kerja Dan Peningkatan Produktivitas".

Penulis ingin mengembangkan sebuah mesin 
penghalus otomatis. Alasan penulis mengembangkan mesin penghalus otomatis ini yaitu dengan keunggulan tingkat akurasi dan presisi yang lebih tinggi, sehingga mempermudah hasil yang diperoleh.

Rumusan masalah yang akan dibahas dalam penelitian ini diantaranya adalah sebagai berikut:

1. Bagaimana cara kerja mesin penghalus permukaan tipe disc dan belt terhadap tingkat kekasaran permukaan benda kerja?

2. Bagaimana pengaruh variasi kecepatan motor pada mesin penghalus permukaan tipe disc dan belt terhadap tingkat kekasaran permukaan benda kerja?

Adapun batasan-batasan masalah dalam penelitian ini adalah:

- Bahan yang digunakan yaitu kayu

- Penggerak menggunakan motor AC $1 / 4 \mathrm{HP}$

- Untuk penggunaan ukuran amplas 30 x $10 \mathrm{~cm}$

- Variasi kecepatan menggunakan Driver Motor.

Tujuan tugas akhir ini adalah untuk mengetahui cara kerja mesin amplas, dan untuk mengetahui pengaruh variasi kecepatan motor pada mesin penghalus permukaan tipe disc dan belt terhadap tingkat kekasaran permukaan benda kerja.

Adapun manfaat penelitian dalam penelitian ini diantaranya yaitu mempercepat pekerjaan yang dilakukan, mengoptimalkan hasil untuk sektor home industry dan membuat sebuah mesin penghalus yang berguna untuk praktikum mahasiswa Teknik Mesin Universitas Muhammadiyah Jember.

\section{METODE PENELITIAN}

\section{Diagram Alir Penelitian}

Adapun diagram alir dalam penelitian ini dalah sebagai berikut:

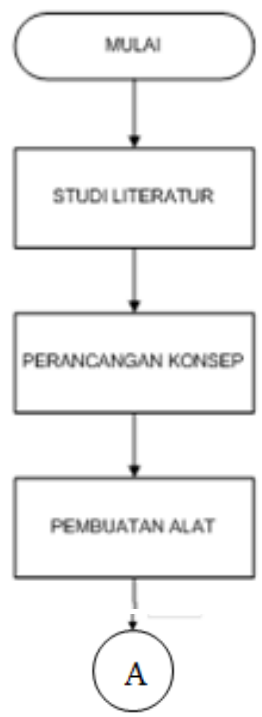

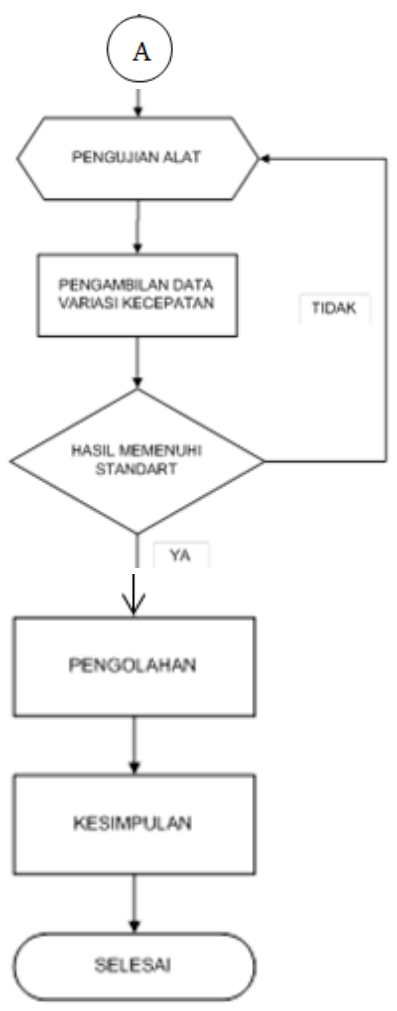

Gambar 1. Diagram Alir Penelitian

\section{Bahan dan Alat Penelitian}

Dalam perancangan dibutuhkan beberapa bahan dan alat untuk mendukung proses pembuatan alat.

\section{Bahan}

1. Amplas dengan panjang $30 \mathrm{~cm}$ dan lebar $10 \mathrm{~cm}$.

2. Kabel 2 meter.

3. Bearing duduk.

4. As poros.

5. Besi untuk rangka.

6. Kayu (benda kerja).

Alat

1. Dinamo AC $1 / 4 \mathrm{HP}$.

2. Driver motor AC.

3. Kunci pas (10 dan 12).

4. Gerinda.

5. Borduduk.

6. Obeng.

7. Tang.

8. Palu.

9. Gunting.

10. Timing LED.

11. Volt meter.

12. Surface Roughness.

Rancangan Struktural Mesin Penghalus Permukaan Tipe Disc Dan Belt Terhadap Tingkat Kekasaran Permukaan Benda Kerja

Pada perancangan dan realisasi mesin penghalus permukaan tipe disc dan belt terhadap permukaan 
bendakerja terdiri dari 2 komponen untuk mendukung kinerja system yaitu driver motor AC, motor (dynamo) AC dan beberapa bahan antara lain amplas, as poros dan bearing. Untuk gambar rangkaian desain alat dapat dilihat pada gambar 2. di bawah ini.

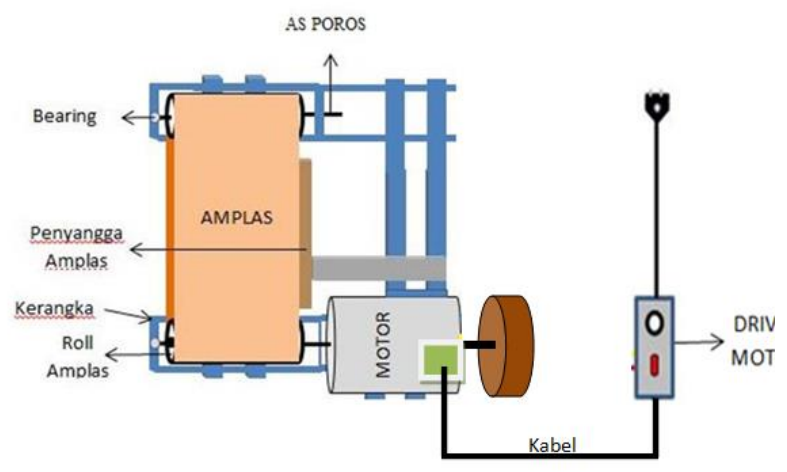

\section{Spesifikasi Mesin}

Untuk spesifikasi pada perancangan mesin penghalus permukaan tipe disc dan belt pada bendakerja akan dijelaskan sebagai berikut:

1. Driver Motor AC

Rangkaian driver yang digunakan disini berfungsi sebagai antarmuka antara mikrokontroler dengan rangkaian daya. Selain berfungsi sebagai antar muka rangkaian in ijuga berfungsi sebagai pengaman (isolasi) antara rangkaian daya dengan mikrokontroler sehingga bila terjadi kerusakan pada rangkaian daya maka mikrokontroler tidak akan mengalami kerusakan.

Driver Motor AC digunakan untuk menaik turunkan speed atau kecepatan dari motor dengan cara menaik turunkan tegangan secara digital tanpa mengurangi arus dari motor. Dengan spesifikasi sebagai berikut:

1. Tegangan input 220 volt

2. Tegangan out put 50 volt -220 volt

3. Daya 2000 watt.

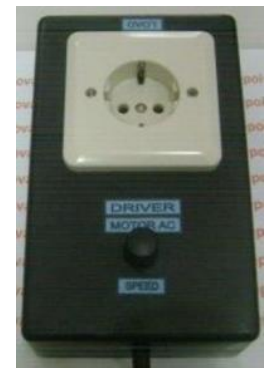

Gambar 3. Komponen Driver Motor AC

\section{Motor AC}

Motor AC bekerja sebagai berikut, yaitu listrik dipasok ke stator yang akan menghasil kan medan magnet. Medan magnet ini bergerak dengan kecepatan sinkron disekitar rotor. Arus rotor menghasilkan medan magnet kedua yang berusaha untuk melawan medan magnet stator, yang menyebab kan rotor berputar. Walaupun begitu, di dalam prakteknya motor tidak pernah bekerja pada kecepatan sinkron namun pada kecepatan dasar yang lebih rendah. Terjadinya perbedaan antara dua kecepatan tersebut disebabkan adanya slip atau geseran yang meningkat dengan meningkatnya beban. Slip hanya terjadi pada motor induksi. Untuk menghindari slip. Fungsi utama dari motor AC, yaitu digunakan untuk penggerak utama dari mesin penghalus dengan spesifikasi sebagai berikut:

1. Rotor perbedaan utama antara sinkron dengan motor induksi adalah bahwa rotor mesin sinkron berjalan pada kecepatan yang sama dengan perputaran medan magnet. Halini memungkinkan sebab medan magnet rotor tidak lagi terinduksi. Rotor memiliki magnet permanen, yang dipaksa untuk mengunci pada posisi tertentu bila dihadapkan dengan medan magnet lainnya.

2. Stator menghasilkan medan magnet berputar yang sebanding dengan frekuensi yang dipatok.

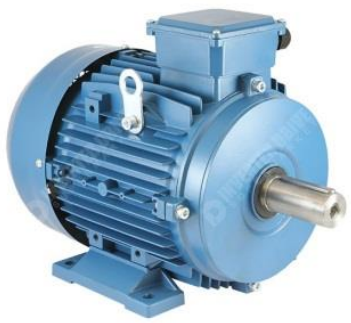

\section{Gambar 4. Komponen Motor AC}

\section{Amplas}

Amplas yaitu bahan dasar utama yang diperlukan untuk pembuatan mesin penghalus otomatis. Fungsi nya yaitu menghaluskan permukaan dari benda kerja. Spesifikasinya yaitu sebagai berikut:

1. Berbentuk persegi panjang dengan ukuran panjang $100 \mathrm{~cm}$ dan lebar $10 \mathrm{~cm}$.

2. Amplas yang digunakan yaitu dengan tingkat kekasaran nomor 300.

4. Bearing Duduk

Bearing Duduk berfungsi untuk membatasi gerak relative antara dua atau lebih komponen mesin agar selalubergerakpadaarah yang diinginkan. Dengan diameter samadenganukuran as poros yaitu $1 \mathrm{~cm}$. 


\section{Roll PemutarAmplas}

Roll pemutar berfungsi untuk menghubungkan putaran amplas dari as poros dengan spesifikasi sebagai berikut:

1. Pada perancangan alat menggunakan 2 buah roll pemutar.

2. Bahan yang digunakan untuk membuat roll yaitu terbuat dari spons agar dapat menghindari slip dari amplas.

3. Diameter dari roll $5 \mathrm{~cm}$.

6. Surface Roughness

Surface roughness merupakan alat yang mampu mengukur tingkat kekasaran permukaan. Setiap permukaan komponen dari sesuatu benda mempunyai beberapa bentuk dan variasi yang berbeda baik menurut strukturnya maupun dari hasil proses produksinya. Roughness didefinisikan sebagai ketidakhalusan buntuk yang menyertai proses produksi yang disebabkan oleh pengerjaan mesin. Nilai kekasaran dinyatakan dalam Roughness Average (Ra). Ra merupakan prameter kekasaran yangpaling banyak dipakai secara internasional. Langkah-langkah pengerjaan dengan alat ini adalah:

1. Benda iji di letakkan pada meja datar.

2. Ujung dari dial indicator diset pada posisi stabil untukmelakukan pembacaan skala tekanan terhadap benda uji.

3. Tentukan seberapa panjangdari bagian benda ukur yang akan diujikekasaran permukaannya.

4. Apabila dial indicator melakukan pengukuran sepanjang jarak yang kita tentukan nilai kekasaran permukaan akaan tercatat dan dapat dilihat dalaam bentuk prin out.

5. Sebelum dilakukan pengukuran, bend uji dan alat ukur tulah diatur sehingga sedapat mungkin tidak terdapat kesalahan dalam pengukuran.

\section{Cara Kerja Mesin}

Proses kerja mesin dilakukan untuk mengetahui apakah mesin sudah berfungsi sesuai dengan yang diinginkan, atau masih terdapat suatu error atau kesalahan baik pada salah satu komponen maupun seluruh sistem yang terdapat dalam mesin penghalus otomatis. Proses pengujian mesin ini dilakukan beberapa kali agar mendapatkan hasil yang lebih maksimal. Proses kerja mesin dimulai dari menghubungkan driver motor AC ke stop kontak dengan tegangan $50-220$ volt. Dan diakhiri pada proses penghalusan benda kerja pada mesin penghalus sampai benda kerja tersebut pada tingkat kehalusan sesuai dengan yang diinginkan. Untuk lebihjelasnya, proses kerja mesin dapat dilihat pada gambar 5. di bawah ini.

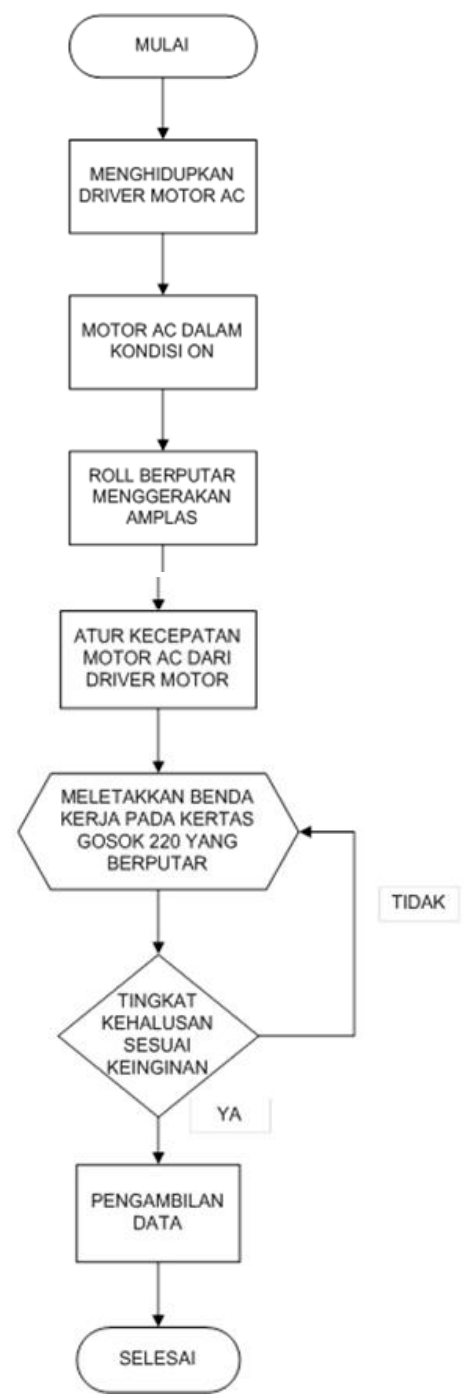

Gambar 5. Diagram Alir Proses Kerja Mesin

Dari diagram alir di atas telah dijelaskan bahwa mesin akan mulai bekerja saat driver motor dihidup kan.Lalu motor AC akan berputar untuk menggerakan roll pemutar amplas. Atur tingkat kecepatan dari motor AC menggunakan potensio yang terhubung dengan driver motor. Tahap berikutnya yaitu hitung waktu penghalusan, kecepatan putaran motor AC, besar daya yang dibutuhkan dan tingkat kehalusan benda kerja. Setelah semua data diperoleh matikan mesin dengan menekan off pada saklar yang terdapat di driver motor.

\section{ANALISA DAN PEMBAHASAN}

Pengujian pertama sistem dilakukan secara terpisah, kemudian selanjutnya dilakukan pengujian secara keseluruhan. Adapun langkah-langkah 
pengujian sistem yang akan dilakukan antara lain :

1. Perancangan desain rangka mesin penghalus.

2. Penghitungan variasi kecepatan RPM mulai dari RPM rendah, sedang dan tinggi.

3. Penghitungan tegangan listrik yang dibutuhkan.

4. Pengujian benda kerja sebelum dan sesudah diuji.

\section{Perancangan Desain Rangka Mesin}

Perancangan dimulai dari pembuatan rangka yang akan dipakai untuk desain mesin penghalus. Perancangan dilakukan dengan tahap pertama yaitu berupa rangka dari besi yang dilas listrik membentuk suatu desain yang telah dibuat sebelumnya menggunakan PC (Personal Computer). Tahap kedua yaitu penggabungan antara alat dan bahan dalam rangka tersebut. Komponen yang dimaksud yaitu motor AC (Dynamo) 220 volt, bearing, as poros dan roll pemutar amplas. Untuk tampilan gambar rangka bisa dilihat pada gambar 6 . dibawah ini.

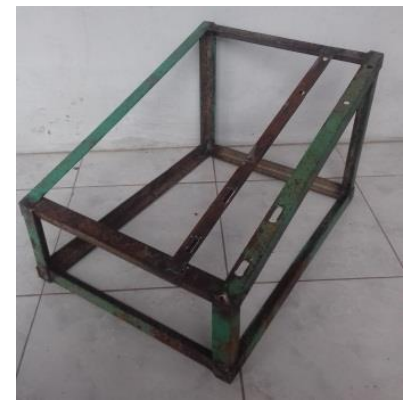

Gambar 6. Desain Rangka Mesin Penghalus

Setelah perancangan rangka selasai dibuat, tahap selanjutnya yaitu pemasangan bahan dan alat. Untuk bahan dan alat dapat dilihat pada tabel 4.1 berikut.

Tabel 1. Bahan dan Alat yang Digunakan

\begin{tabular}{|c|c|}
\hline Bahan & Alat \\
\hline 2 buah jenis Amplas & Dinamo AC \\
\hline Kabel & Driver Motor AC \\
\hline Bearing & Tachometer \\
\hline As poros & AVO meter \\
\hline 3 buah roll pemutar amplas & Terminal listrik T \\
\hline
\end{tabular}

Dengan penjelasan 2 buah jenis amplas yang berbeda, amplas pertama berbentuk persegi panjang dengan ukuran $68 \times 8 \mathrm{~cm}$ dan amplas kedua berbentuk lingkaran dengan diameter $16,8 \mathrm{~cm}$, dengan tingkat kekasaran amplas yaitu 220. Untuk 3 buah roll pemutar amplas berbentuk lingkaran. 2 buah berukuran sama yaitu berdiameter $7 \mathrm{~cm}$ sedangkan 1 buah lebih besar berukuran diameter $16,5 \mathrm{~cm}$. Untuk pemasangannya dilakukan bertahap yaitu, pertama memasang bearing, as poros dan roll pemutar amplas pada bagian atas rangka. Selanjutnya pemasangan motor AC yang disambung dengan roll pemutar dibagian bawah rangka. Seperti terlihat pada gambar 7. berikut.

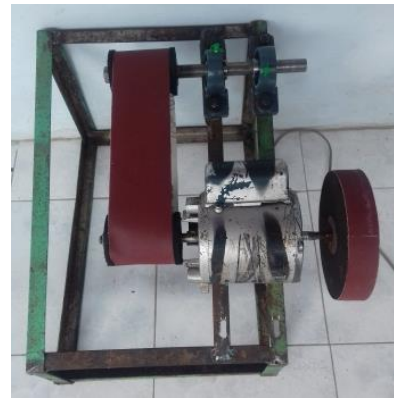

Gambar 7. Tampilan Mesin Penghalus Tipe Disc dan Belt

\section{Penghitungan Variasi Kecepatan RPM}

Pengujian ini dilakukan untuk mengetahui tingkat kecepatan mesin penghalus otomatis terhadap benda kerja. Benda kerja yang dipakai berjumlah 3 buah balok kayu berukuran awal panjang $3,5 \mathrm{~cm}$ dan masing-masing benda kerja mendapatkan kecepatan yang berbeda-beda. Yaitu kecepatan rendah dengan kecepatan 1100 RPM, kecepatan sedang 1300 RPM dan kecepatan tinggi 1500 RPM. Tiap pengujian masing-masing dilakukan dalam waktu 1 menit. Hasil pengujian dapat dilihat pada tabel 4.2 sebagai berikut.

Tabel 2. Hasil Pengujian Alat

\begin{tabular}{|c|c|c|c|c|c|}
\hline $\begin{array}{c}\text { No. } \\
\text { Kayu }\end{array}$ & $\begin{array}{c}\text { Panjang } \\
\text { kayu } \\
\text { awal (cm) }\end{array}$ & $\begin{array}{c}\text { Waktu } \\
\text { (detik) }\end{array}$ & $\begin{array}{c}\text { Kecepatan } \\
\text { (RPM) }\end{array}$ & $\begin{array}{c}\text { Panjang kayu } \\
\text { akhir (cm) }\end{array}$ & $\begin{array}{c}\text { Keausan } \\
\text { (cm) }\end{array}$ \\
\hline A1 & 3,008 & 60 & 1100 & 3,012 & 0,004 \\
\hline A2 & 3,008 & 60 & 1100 & 3,012 & 0,004 \\
\hline A3 & 3,008 & 60 & 1100 & 3,012 & 0,004 \\
\hline B1 & 3,008 & 60 & 1300 & 3,002 & 0,006 \\
\hline B2 & 3,008 & 60 & 1300 & 3,002 & 0,006 \\
\hline B3 & 3,008 & 60 & 1300 & 3,002 & 0,006 \\
\hline C1 & 3,008 & 60 & 1500 & 2,988 & 0,02 \\
\hline C2 & 3,008 & 60 & 1500 & 2,988 & 0,02 \\
\hline C3 & 3,008 & 60 & 1500 & 2,988 & 0,02 \\
\hline
\end{tabular}

Dengan rumus keausan:

Panjang kayu awal (mm) - panjang kayu akhir (mm) = tingkat keausan $(\mathrm{mm})$

Dari pengujian ini dapat diketahui bahwa semakin tinggi tingkat kecepatan mesin penghalus maka semakin besar tingkat keausan benda kerja.

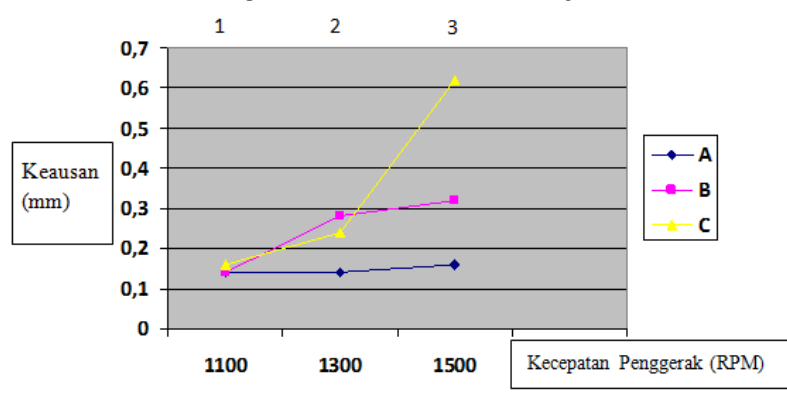

Gambar 8. Grafik Variasi Kecepatan 


\section{Penghitungan Tegangan Listrik yang Dibutuhkan}

Pada tahap ini di lakukan penghitungan voltase listrik yang dibutuhkan mesin penghalus pada kecepatan rendah, sedang dan tinggi. Pengujian ini dilakukan dalam waktu 1 menit. Alat yang digunakan untuk mengukur besaran tegangan listrik yaitu menggunakan AVO meter digital. Dalam rentang kecepatan putaran 1100 RPM, 1300 RPM dan 1500 RPM. Untuk hasil pengujian besaran tegangan listrik dapat dilihat pada tabel 4.3 sebagai berikut.

Tabel 3. Besaran Tegangan Listrik yang Dibutuhkan

\begin{tabular}{|c|c|c|}
\hline $\begin{array}{c}\text { Kecepatan Putaran } \\
\text { (RPM) }\end{array}$ & $\begin{array}{c}\text { Waktu } \\
\text { (detik) }\end{array}$ & $\begin{array}{c}\text { Tegangan } \\
\text { (volt) }\end{array}$ \\
\hline 1100 & 60 & 110 \\
\hline 1300 & 60 & 150 \\
\hline 1500 & 60 & 200 \\
\hline
\end{tabular}

Dalam pengujian pada tabel diatas dapat diketahui bahwa semakin tinggi putaran mesin maka semakin besar pula tegangan listrik yang dibutuhkan. Dari pengujian ini dapat ditarik kesimpulan bahwa mesin penghalus otomatis ini dapat memperkecil tegangan listrik yang dibutuhkan sehingga dapat menghemat atau memperkecil biaya pengeluaran tagihan listrik.

\section{Pengujian Benda Kerja Sebelum dan Sesudah Diuji}

Pada tahap ini penulis menggunakan benda kerja kayu berbentuk balok dengan ukuran panjang awal $3,5 \mathrm{~cm}$. Benda kerja yang dipakai berjumlah 9 buah balok kayu dan dibagi menjadi 3 bagian. Bagian A mendapatkan tingkat kecepatan putaran mesin sebesar 1100 RPM. Bagian B mendapatkan tingkat kecepatan putaran mesin sebesar 1300 RPM. Dan bagian C mendapatkan tingkat kecepatan putaran sebesar 1500 RPM. Masing-masing bagian terdiri dari 3 buah balok kayu. Pada tingkat kekasaran awal, tingkat kekasaran pada 9 benda kerja disamakan pada nilai rata-rata 8,531 $\mu \mathrm{m}$ untuk kesembilan benda kerja. Dengan cara diamplas dengan menggunakan mesin penghalus untuk mencapai nilai kekasaran yang sama pada ke-9 benda kerja yang akan diuji. Untuk tampilan awal benda kerja sebelum diuji dapat dilihat pada gambar 9. sebagai berikut.

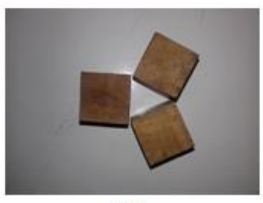

(a)

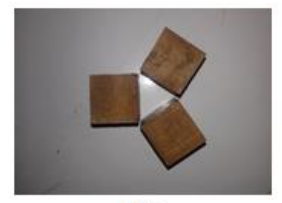

(b)

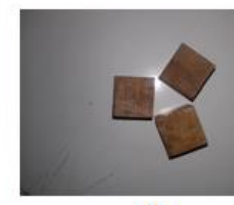

(c)
Gambar 9. Bagian (a), Bagian (b), Bagian (c) Sebelum Diamplas

Dengan perincian sebagai berikut:
1. Bagian A mendapat kecepatan putaran mesin mencapai 1100 RPM (putaran rendah).

2. Bagian B mendapat kecepatan putaran mesin mencapai 1300 RPM (putaran sedang).

3. Bagian $\mathrm{C}$ mendapat kecepatan putaran mesin mencapai 1500 RPM (putaran tinggi).

Desain ukuran benda kerja yaitu ditunjukan pada gambar 10. sebagai berikut:

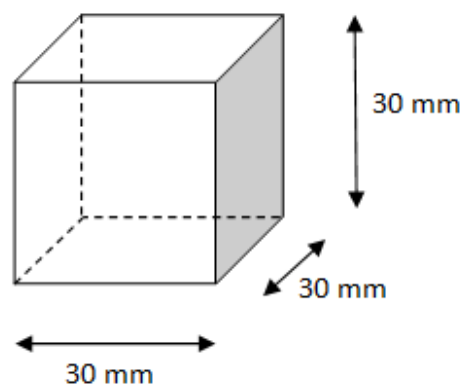

Gambar 10. Ukuran Keseluruhan Benda Kerja

Untuk tampilan benda kerja yang sudah di amplas dengan nilai kekasaran nya dapat dilihat pada gambar 11. sebagai berikut.

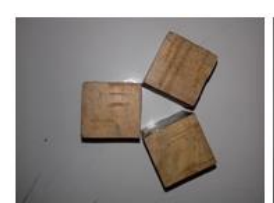

(a)

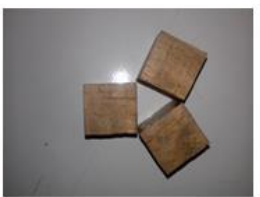

(b)

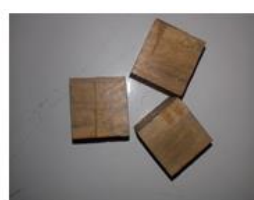

(c)
Gambar 11. Permukaan (a), (b), (c) yang Sudah Diamplas

\section{Hasil Pengujian Tingkat Kekasaran}

Pada tahap ini dilakukan pengujian pada tingkat kekasaran benda kerja yang dipakai dalam proses pengujian alat. Benda kerja yang diuji berjumlah 9 kubus kayu dan dibagi menjadi 3 kelompok yaitu kelompok A, B dan C. Data yang diperoleh berdasarkan perhitungan awal nilai kekasaran benda kerja sebelum dan sesudah diuji. Untuk data nilai kekasaran dapat dilihat pada tabel 4.4 dibawah ini.

Tabel 4. Rata-Rata Pengujian Hasil Kekasaran

\begin{tabular}{|c|c|c|c|c|c|}
\hline \multicolumn{2}{|c|}{$\begin{array}{c}\text { Spesimen } \\
\text { kayu }\end{array}$} & $\begin{array}{c}\text { Kecepatan } \\
\text { (RPM) }\end{array}$ & $\begin{array}{c}\text { Ra } \\
\text { sebelum } \\
(\mu \mathrm{m})\end{array}$ & $\begin{array}{c}\text { Ra } \\
\text { sesudah } \\
(\mu \mathrm{m})\end{array}$ & $\begin{array}{c}\text { Rata - rata kekasaran pada } \\
\text { tingkat kecepatan sesudah } \\
\text { pengujian }\end{array}$ \\
\hline \multirow{3}{*}{ A } & 1 & \multirow{3}{*}{1100} & 8,531 & 5,068 & \multirow{3}{*}{4,438} \\
\hline & 2 & & 8,531 & 4,128 & \\
\hline & 3 & & 8,531 & 4,120 & \\
\hline \multirow{3}{*}{ B } & 1 & \multirow{3}{*}{1300} & 8,531 & 3,492 & \multirow{3}{*}{3,428} \\
\hline & 2 & & 8,531 & 3,232 & \\
\hline & 3 & & 8,531 & 3,561 & \\
\hline \multirow{3}{*}{ C } & 1 & \multirow{3}{*}{1500} & 8,531 & 2,796 & \multirow{3}{*}{3,047} \\
\hline & 2 & & 8,531 & 3,083 & \\
\hline & 3 & & 8,531 & 3,261 & \\
\hline
\end{tabular}


Perubahan rata-rata kekasaran pada setiap masingmasing kecepatan ditunjukan pada grafik dibawah.

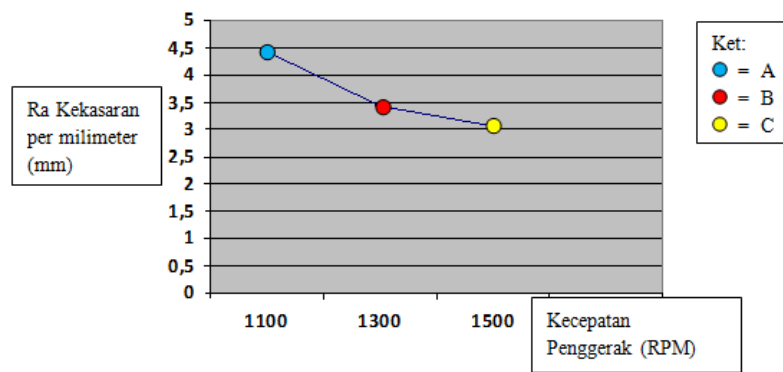

Gambar 12. Grafik Rata-Rata Tingkat Kekasaran Benda Kerja

\section{PENUTUP}

\section{Kesimpulan}

Berdasarkan hasil analisa dan pembahasan diperoleh beberapa kesimpulan antara lain:

1. Dengan menggunakan driver motor mesin penghalus dapat diatur kecepatannya mulai dari kecepatan 1100 RPM, 1300 RPM dan 1500 RPM sesuai keinginan.

2. Dengan mengatur kecepatan putaran motor, mesin penghalus dapat meminimalisir pasokan tegangan listrik yang dibutuhkan sehingga dapat menghemat pengeluaran.

3. Pada tingkat kecepatan putaran 1100 RPM menghasilkan rata-rata kekasaran 4,438 $\mu \mathrm{m}$, pada tingkat kecepatan putaran 1300 RPM menghasilkan rata-rata kekesaran 3,428 $\mu \mathrm{m}$ dan pada tingkat kecepatan putaran 1500 RPM menghasilkan rata-rata kekasaran 3,047 $\mu \mathrm{m}$. Semakin rendah putaran mesin maka semakin kasar permukaan benda kerja yang diuji, sedangkan semakin tinggi putaran mesin maka semakin halus hasil yang didapat.

4. Pada tingkat kecepatan putaran 1100 RPM menghasilkan rata-rata tingkat keausan 0,0213 $\mathrm{cm}$, pada tingkat kecepatan putaran 1300 RPM menghasilkan rata-rata tingkat keausan $0,022 \mathrm{~cm}$ dan pada tingkat keepatan putaran 1500 RPM menghasilkan rata-rata tingkat keausan $0,036 \mathrm{~cm}$. Ketika putaran tinggi maka tingkat keausan akan lebih besar, sedangkan ketika putaran rendah tingkat keausan akan lebih kecil.

5. Alat ini sangat sesuai untuk pengerjaan kerajinan berbahan dasar kayu yang lebih efektif karena dengan mengontrol kecepatan putaran motor sehingga dapat meminimalisir biaya pengeluaran listrik. Serta dengan nilai keausan yang dapat disesuaikan dengan tingkat kecepatan putarannya sehingga kita bisa mendapatkan tingkat kekasaran permukaan benda kerja sesuai keinginan.

\section{Saran}

Penelitian ini merupakan hasil maksimal saat ini. Karya ini masih bisa dikembangkan untuk kedepannya, adapun saran yang dapat diberikan yaitu sebagai berikut:

1. Perancangan mesin dapat ditambahkan dengan menambahkan pegas untuk penekanan yang lebih efisien agar stabil saat ditekan dan mendapatkan hasil yang maksimal.

2. Untuk daya motor dapat diganti dengan tegangan DC, sehingga mesin dapat dioperasikan kapanpun dan dimanapun tanpa tergantung pada listrik PLN.

\section{DAFTAR PUSTAKA}

Sofwan, A.(2004). Sistem Pengendalian Kecepatan Putaran Phasa Satu Menggunakan Mikrokotroller AT89S8252. Jakarta: Universitas Gunadarma.

Kristianto, Agung. (2012). Perancangan Ulang Mesin Amplas Kayu Profil Lengkung Untuk Perbaikan Posisi Kerja Dan Peningkatan Produktivitas. Yogyakarta: Universitas Ahmad Dahlan.

Hardiati, Sri.(2009). Pengendali Kecepatan Motor Induksi 3-Phase Pada Aplikasi Industri Plastik. Jakarta: Pusat Penelitian Elektronika Dan Telekomunikasi - LIPI.

Adhi, Dianasa Saputra. (2009). Perancangan Meja Dan Kursi Kerja Yang Ergonomis Pada Stasiun Kerja Pemotongan KerupukSebagai Upaya Peningkatan Produktivitas. Yogyakarta: Universitas Ahmad Dahlan.

Gumanto. (2009). Perancangan Meja Gergaji Untuk Meminimalkan Kelelahan Operator. Yogyakarta: Universitas Ahmad Dahlan. 
